\title{
Effectiveness of policy regarding power supply to schools through solar energy: Using solar panels to increase enrolment at schools in Pakistan
}

\author{
Abbas Ali Gillani ( $\square$ abbasaligillani@gmail.com ) \\ Institute of Business Administration Karachi: Institute of Business Administration \\ https://orcid.org/0000-0002-2375-6455
}

\section{Sana Khan}

Institute of Business Administration Karachi: Institute of Business Administration

\section{Sadia Nasir}

Institute of Business Administration Karachi: Institute of Business Administration

\section{Salwa Niaz}

Institute of Business Administration Karachi: Institute of Business Administration

\section{Original article}

Keywords: Climate change, solar energy, policy, education, enrolment

Posted Date: February 23rd, 2021

DOI: https://doi.org/10.21203/rs.3.rs-201284/v1

License: (9) This work is licensed under a Creative Commons Attribution 4.0 International License. Read Full License 


\section{Abstract}

Background: Climate change has adversarial impact on social and economic development, with negative consequences on living conditions, health outcomes and labour productivity. Although there is ample literature that highlights the use of renewable energy, especially solar energy, in mitigating the effects of climate change, empirical evidence linking benefits of renewable energy with educational access and attainment is very limited.

Results: By using school level data between 2013-18 from Pakistan, this paper estimates the effectiveness of the policy regarding power supply to schools through solar energy on enrolment. Using a difference-in-difference estimation and controlling for school-specific and infrastructure-specific characteristics, we show that average enrolment per school in Punjab increased by 48.5 students, compared to average enrolment per school elsewhere in Pakistan, after the policy of installing solar panels at schools in Punjab was announced. Furthermore, gender-wise breakup of results suggest that the policy resulted in increased enrolment for boys' schools, girls' school and mixed-gender schools. The results are consistent when standard errors are normal, robust, or clustered at the province level.

Policy implications: Limitation of the study includes unidentified mechanisms for the policy effect and heterogeneous effects on gender, which should be the focus of future research.

\section{Introduction}

It is becoming increasingly evident that climate change has adversarial impact on social and economic development (Fritsche et al., 2012; Sachs, 2008; Scheffran et al., 2011; Bosello et al., 2006), with negative effects on living conditions (Parry et al., 2004; Bloem et al., 2010; Anand et al., 2011), health outcomes (Vardoulakis et al., 2015; Patz et al., 2005; Zhou et al., 2008; Burkey et al., 2018) and labour productivity (Ranjan et al., 2013; Ahmed at al., 2013; Morton, 2007). With regards to living conditions, climate change is significantly modifying environmental setup and temperature (Tol, 2009; Baldrian et al., 2013; Xu et al., 2009), natural resources and production capabilities (Saseendran et al., 2000; Ranjan et al., 2006; Arnell et al., 2006;) and global food supply (Wheeler et al. 2013; St. Clair et al., 2010; Tirado et al., 2015). Even for health outcomes, climate change is linked to rise in infections and diseases (Bradley et al., 2005; Wu et al., 2015; Rohayem, 2009; Kinney et al., 2008), deteriorating mental health (Berry et al., 2010; Fritze et al., 2008; Bourque et al., 2014) and increase in concerns related to child health and nutrition. (Thompson et al., 2013; Llyod et al., 2011; Bunyavanich et al., 2003). However, there is little empirical research on how climate change may impact educational outcomes (Sheffield et al., 2017). It is possible that climate change may act as a barrier to educational access thus resulting in low enrolment at schools (Haurin, 2017; Randell et al., 2019), or displace students and teachers permanently (Anderson, 2019) or lead to lower academic performance (Randell et al., 2016; Chuang et al., 2018).

One of the leading causes of climate change is the increased levels of green-house gas emissions resulting in global warming, with the amount of emissions exponentially rising in the recent decades 
(Ritchie et al., 2017). Since the industrial revolution, the rapid increase in the carbon dioxide emissions alone have peaked to their highest level in at least two million years (Climate Central, 2019). The primary source of human-generated emissions is the burning of non-renewable energy resources such as oil, coal and gas, for the purpose of large-scale manufacturing, transportation and generation of electricity (Denchak, 2017). This means, if renewable energy i.e. wind, hydel or solar can be used as an alternative to burning non-renewable resources, it may restrict green-house gas emissions, and combat climate change (Haines et al., 2006). Solar energy, in particular, is often regarded as a technological solution to reduce air pollution, expand access to energy for all, and hence mitigate climate change (Pjeczka, 2018). Along with reducing emission of green-house gases, solar energy technology has positive implications on reclamation of degraded land, reduction in the required transmission lines of the electricity grids and improvement of the quality of water resources (Tsoutsos et al., 2005). Moreover, through technological advancements, expanding markets and government subsidies and incentives, solar-technology cost has declined thus helping homes and business in remote locations to save money by going off-grid with small-scale solar installations (Shaw, 2017). However, the benefits of producing energy through solar power comes at a cost. Manufacturing of solar panels require caustic chemicals, with the process using large amounts of water and electricity (Nunez, 2014). Similarly, solar panel waste may contain substantial quantities of glass, plastic and toxic material, which cannot be disposed of without environmental hazard (Shellenberger, 2018). Also, products such as the solar oven which are intended to lower non-renewable fuel consumption and time spent collecting fuel may achieve the desired results as they fail to reduce indoor air pollution or generate a sizeable decrease in fuel use (Beltramo et al., 2013).

Climate change could directly cost the world economy 7.9 trillion dollars by 2050 , along with rising temperatures leading to 3 per cent of global gross domestic product being wiped out (Galey, 2019). Moreover, in the next two decades, climate change is expected to cause additional 250,000 deaths per year, with direct damage costs to health estimated between 2 to 4 billion dollars a year (World Health Organization, 2018). Individuals events such as wildfires in Australia that burnt 50 million acres of land and killed 34 people (Fountain, 2020), floods in UK that cost the economy up to 14 billion dollars (United Nations, 2014), shrinking of Greenland's ice sheet by 600 billion tons (Welle, 2020) and extreme weathers that cost the US economy at least 240 billion dollars a year (Leahy, 2017), have all been linked to climate change. In the meantime, solar power has become the cheapest mode of power generation in Germany, with solar panels producing 8 per cent of the country's net power consumption and renewable energy accounting for 43 per cent of the total (Wehrmann, 2018). In Japan too, the total share of solar power generation stood at 6.5 per cent in 2018, compared to 1.9 per cent in 2014, while non-renewable power generation declined from 87.9 per cent in 2014 to 77.9 per cent in 2018 (Institute for Sustainable Energy Policies, 2019). Lastly, the number of people getting electricity is exceeding the population growth in SubSaharan Africa, owing to the 700,000 on site solar systems that have been installed, and African governments initiative to reach 1,000 mega-watts in all of solar power by 2023, which would deliver electricity to 56 million new users (Silverstein, 2019).

Although there is sufficient literature that highlights the positive impact of using renewable energy resources such as solar power, the evidence is not without limitations. Using the capacity targets of the 
photovoltaic and concentrated solar power plants, the employment effects of solar energy industry in Turkey are determined (Cetin et al., 2011). They conclude that solar energy in Turkey would be the primary source of energy demand and would have big employment effects on the economics. However, the achieved targets can only be achieved with the support of governmental feed-in-tariff policies of solar energy and by increasing research-development funds. Moving on, Wiser et al. (2016) study the environmental and public health benefits of achieving high penetrations of solar energy in the US. They find that with feasible cost reductions, solar power can provide major environmental benefits, along with air quality, public health benefits and reduced power-sector water withdrawals and consumption. Moreover, the success of the UK policy to reduce carbon emissions has been partly attributed to successful persuasion of households to become more energy sufficient, and to encourage installation of domestic solar systems (Faiers et al., 2006). However, since the financial, economic and aesthetic characteristics of adopting solar systems are only viewed plausible by a small fraction of the population, emphasis on marketing and development of solar products must be made. Furthermore, by conducting a randomized field experiment in India to estimate the causal effects of off-grid solar power on electricity access and broader socioeconomic development, Aklin et al. (2017) reveal that daily hours of access to electricity only increased marginally, whereas kerosene expenditure on the black market only decreased slightly. At the same time, no systemic evidence for changes in savings, spending, business creation or time spent working or studying were found. Finally, Aevarsdottir et al. (2017) provide experimental evidence on the impacts of non-grid small scale electrification by offering randomized subsidies towards a solar lamp with a mobile phone charging point to hosueholds in Tanzania. They find that lamps, along with positively affecting expenditure on lighting and mobile phone charging, also impacted labour supply, household income and well-being. Additionally, they find significant positive effects on health in the subsample of households that did not previously own a solar lamp.

Using school level data of 21,412 schools across 176 districts of Pakistan from years 2013 till 2018, we examine the effectiveness of the policy regarding power supply to schools through solar panel. By using a difference-in-difference estimation and controlling for school-specific and infrastructure-specific characteristics, we estimate whether the policy resulted in differential in enrolment between schools belonging to province of Punjab, where the policy was implemented, and elsewhere in Pakistan, where the policy was not implemented. As a result, our sample size can be divided into 5,444 schools from Punjab being part of the treatment schools, while 15,968 schools from elsewhere in Pakistan are part of the control schools. We provide conclusive evidence that the policy of installing solar panels in schools of Punjab resulted in higher enrolment, compared to enrolment in schools elsewhere in Pakistan. In particular, average enrolment per school in Punjab increased by 48.5 students, compared to average enrolment per school elsewhere in Pakistan, after the implementation of the policy. Gender-wise breakup of results shows that for boys' schools, average enrolment per school in Punjab increased by 24.1 students, compared to average enrolment per school elsewhere in Pakistan, after the implementation of the policy. At the same time, for girls' schools too, average enrolment per school in Punjab increased by 48.5 students, compared to average enrolment per school elsewhere in Pakistan, after the implementation of the policy. Similarly, for mixed-gender schools also, average enrolment per school in Punjab increased 
by 54.1 students, compared to average enrolment per school elsewhere in Pakistan, after the implementation of the policy. The results are consistent when standard errors are normal, robust, or clustered at the province level.

Mekhilef et al. (2011) point out that with the increasing popularity in industrial application, solar thermal is an alternative to generate electricity, process chemicals and even space heating. At the same time, solar electricity can be widely applied in telecommunication, agriculture, textile and water desalination. They highlight that according to International Energy Agency, by 2050, solar array installations will supply around 45 per cent of energy demand in the world. Mondal et al. (2011) find the impacts of solar home systems (SHSs) application in Bangladesh and reveal that under the SHSs, women and children benefitted from the improved quality of life for household work and studying in the evening. Moreover, users of SHSs became accustomed to the better quality of light as solar electrification added to the overall comfort and satisfaction of the households. Jacobson (2007) conclude that while income and work related uses of solar lighting in Kenya are modest, education uses are more significant. However, solar electrification may potentially contribute to sustainable development, but concerns about equity and other social issues need careful attention. In India, Buragohain (2012) examines the impact of installing solar photovoltaic home lighting systems under the 'Remote Village Electrification Program'. The study reports that the Program led to significant improvement in children's education, along with improvement in standard of living. Beneficiaries of the Program spent more time on income generating activities while crime rate also declined due to availability of solar lights in the village.

This paper adds to the debate on the advantages of renewable energy, especially solar power, by exploring a substantial gap in the literature related to the impact of solar energy on educational access and attainment. Literature on the effectiveness of solar energy in lowering barriers to entry to schooling, along with improving supply-side determinants, is very limited and scattered. By using an extensive dataset related to schools, and a uniquely identified policy in favour of providing power supply to schools through solar energy, this paper provides quantitative evidence that solar energy can drive enrolment at schools, especially in countries where barriers to entry in education are high. Countries like Pakistan, which are facing severe challenges in achieving Sustainable Development Goal related to universal access to free, quality and equitable schooling, can benefit greatly from technologically-advance alternate methods of power generation to schools, especially in areas with large populations cut-off from the ongrid electrification. At the moment, due to global warming and extreme weathers, Pakistan is on the trajectory of becoming uninhabitable by the end of the century (Worland, 2017) whereas severe energy crises and electrcitiy shortfall has only hindered social and economic development (Ahmed et al., 2015). These facts point towards immediate inclusion of renewable energy as a viable source of power generation, although there is need to scale-up research in the development of renewable energy in order to better inform energy policies.

The paper is structured as follows: Section II explains the background of the solar power policy implemented in Punjab province of Pakistan. Section III describes the dataset and provides descriptive 
statistics while Section IV discusses the identification strategy applied for our estimations. Results are presented in Section V while Section VI concludes the paper.

\section{Background Of Policy Regarding Power Supply To Schools Through Solar Energy}

On his visit to China in early 2014, the Chief Minister of Government of Punjab province, Shahbaz Sharif, met with potential investors belonging to different energy companies, financial institutions and development agencies, and discussed various proposals for investment in coal, hydel and solar power projects in Punjab (Pakistan Today, 2014). Due to the high energy consumption, the Government of Punjab was exploring various options to increase electricity production to cater to the demand of the province. By late 2014, Government of Punjab had selected 46 sites in the province to set up small-scale solar power projects aimed at reducing power shortages (The Express Tribune, 2014). Power shortages had been linked to having a negative impact on health, agriculture and education sector. A few months later, the Government of Punjab communicated that a strategy was being devised to install solar panels in primary schools to ensure uninterrupted power supply to schools (Geo News, 2014). In early 2015, Shahbaz Sharif officially announced that 4,000 primary schools in rural Punjab would use solar power under the first phase of the Off-Grid Solar Solution program (The Express Tribune, 2015). Under the program, immediate installation of solar panels would take place at the chosen schools to ensure continuous provision of electricity. By mid-2015, the Government of Punjab communicated that 10,000 schools were being shifted to solar energy in the province, half of which did not have electricity (Pakistan Today, 2015). With the financial assistance provided by Asian Development Bank, the project was completed by the end of 2015 (The News, 2016). With the successful completion of the project, the Government of Punjab launched its second program, Khadim-e-Punjab Ujala Program, that would solarize 20,000 schools in the entire province, focusing on remote areas (Associated Press of Pakistan, 2017).

The purpose of the project was not only to improve the power supply to schools, but also raise awareness about solar energy as an alternative energy source. With the success of the first program, along with less than 50 per cent of the population of entire Pakistan connected to the national grid, and Pakistan being heavily dependent on imported electricity, the program attracted support from international financing agencies such as Asian Development Bank and AFD Bank of France (Climate Action, 2017). In conclusion, the policy of shifting schools on solar energy was formulated, and initiated, in 2015, following which schools were provided electricity from solar energy in academic year 2016 onwards.

\section{Data And Descriptive Statistics}

Data used for this study is provided by Annual Status of Education Report (ASER) Pakistan. ASER Pakistan is part of a South-South initiative across India, Kenya, Mali, Mexico, Senegal, Tanzania and Uganda, aimed at addressing quality, accountability and governance in education. ASER Pakistan is the largest citizen led, household based initiative in Pakistan, and is active in all the districts of Pakistan. Each year, 30 villages per district are selected randomly using the Probability Proportional to Size (PPS) 
technique from the village directory of the 1998 Population Census. From each selected village, one government school is chosen, resulting in an average of 4,500 schools chosen every year across Pakistan. Moreover, each year, 20 villages from the previous year are retained and 10 new villages are added. The data used for this study is from year 2013 till 2018, with the exclusion of 2017 as ASER did not release any statistics related to education in that year.

\section{Enrolment per school in Punjab and elsewhere in Pakistan}

We first provide descriptive analysis of our main outcome variable, enrolment at school, for schools in Punjab, the province where the policy regarding power supply to schools through solar energy was announced, and for schools elsewhere in Pakistan. Our data divides enrolment at school into four different categories i.e. enrolment per school for all schools, enrolment per school for only boys' schools, enrolment per school for only girls' schools and enrolment per school for only mixed schools. Year-wise trend of enrolment at school for all four categories is provided in Table1.

Table 1: Year-wise descriptive statistics of enrolment at school

\begin{tabular}{|c|c|c|c|c|c|}
\hline Variable & 2013 & 2014 & 2015 & 2016 & 2018 \\
\hline \multicolumn{6}{|l|}{ ENROLMENT PER SCHOOL } \\
\hline $\begin{array}{l}\text { Average enrolment per school of all } \\
\text { schools in Punjab }\end{array}$ & 370.4 & 328.5 & 329.7 & 312.2 & 330.5 \\
\hline $\begin{array}{l}\text { Average enrolment per school of all } \\
\text { schools elsewhere in Pakistan }\end{array}$ & 182.3 & 184.1 & 163.6 & 152.0 & 161.4 \\
\hline $\begin{array}{l}\text { Average enrolment per school of only } \\
\text { boys' schools in Punjab }\end{array}$ & 393.1 & 362.3 & 201.0 & 206.0 & 232.8 \\
\hline $\begin{array}{l}\text { Average enrolment per school of only } \\
\text { boys' schools elsewhere in Pakistan }\end{array}$ & 197.2 & 194.5 & 133.6 & 137.6 & 130.5 \\
\hline $\begin{array}{l}\text { Average enrolment per school of only } \\
\text { girls' schools in Punjab }\end{array}$ & 424.6 & 352.5 & 380.6 & 371.8 & 367.9 \\
\hline $\begin{array}{l}\text { Average enrolment per school of only } \\
\text { girls' schools elsewhere in Pakistan }\end{array}$ & 224.0 & 270.4 & 171.1 & 161.7 & 171.8 \\
\hline $\begin{array}{l}\text { Average enrolment per school of only } \\
\text { mixed schools in Punjab }\end{array}$ & 248.3 & 249.2 & 398.9 & 365.9 & 391.2 \\
\hline $\begin{array}{l}\text { Average enrolment per school of only } \\
\text { mixed'schools elsewhere in Pakistan }\end{array}$ & 143.8 & 159.5 & 209.6 & 153.2 & 187.3 \\
\hline
\end{tabular}

Table 1 suggests that, overall, average enrolment per school in Punjab was higher than average enrolment per school elsewhere in Pakistan, the same difference differential being observed for boys' school, girls' school and mixed schools. Moreover, for schools in Punjab and elsewhere in Punjab, average enrolment per school for boys' school declined considerably from 2014 onwards. Average 
enrolment per school of only boys' schools in Punjab declined from 362.3 students in 2014 to 206.0 students in 2016, before increasing slightly to 232.8 students in 2018 . At the same time, average enrolment per school of only boys' schools elsewhere in Pakistan declined from 194.5 students in 2014 to 130.5 students in 2018. On the other hand, for schools in Punjab and elsewhere in Punjab, average enrolment per school for girls' school did not follow any consistent pattern. Average enrolment per school of only girls' schools in Punjab declined from 424.6 students in 2013 to 352.5 students in 2014, before increasing slightly to 280.6 students in 2015 , and then decreasing again to 367.9 students in 2018. Average enrolment per school of only girls' schools elsewhere in Pakistan increased from 224.0 students in 2013 to 270.4 students in 2014, before declining considerably to 161.7 students in 2016, and then increasing again to 171.8 students in 2018. Lastly, for schools in Punjab and elsewhere in Punjab, average enrolment per school for mixed schools also did not follow any consistent pattern. Average enrolment per school of only mixed schools in Punjab increased from 248.3 students in 2013 to 398.9 students in 2015, before decreasing to 365.9 students in 2016, and then increasing again to 391.2 students in 2018. Similarly, average enrolment per school of only mixed schools elsewhere in Pakistan increased from 143.8 students in 2013 to 209.6 students in 2015, before declining considerably to 153.2 students in 2016, and then increasing again to 187.3 students in 2018. We provide a year-wise trend of enrolment at school for all four categories in Figure 1.

\section{School-specific characteristics}

Descriptive statistics on school-specific characteristics are presented in Table 2. School-specific characteristics include type of school, medium of instruction at school, grade-level of school and total number of teachers at school. Type of school contain information on whether a school is only for boys, or only for girls, or mixed-gender. Similarly, grade-level of school shows whether a school is up till primary-level, or up till secondary-level school, or up till high school, or any other grade-level school. Moreover, medium of instruction at school demonstrates whether learning at school is in English, or in Urdu, or in regional language Pashto and Sindhi, or in any other regional language. Finally, teachers at school represent total teachers appointed at school.

Table 2: Year-wise descriptive statistics of school-specific characteristics 


\begin{tabular}{|c|c|c|c|c|c|}
\hline Variable & 2013 & 2014 & 2015 & 2016 & 2018 \\
\hline \multicolumn{6}{|l|}{ TYPE OF SCHOOL } \\
\hline Total boys' schools & 2,251 & 2,147 & 1,518 & 1,386 & 1,325 \\
\hline Per cent of schools which are boys & 53.47 & 49.91 & 32.86 & 34.60 & 31.00 \\
\hline Total girls' schools & 669 & 759 & 2,355 & 1,910 & 2,207 \\
\hline Per cent of schools which are girls & 15.89 & 17.64 & 50.97 & 47.68 & 51.64 \\
\hline Total mixed schools & 1,290 & 1,396 & 747 & 710 & 742 \\
\hline Per cent of schools which are mixed & 30.64 & 32.45 & 16.17 & 17.72 & 17.36 \\
\hline \multicolumn{6}{|l|}{ GRADE-LEVEL OF SCHOOL } \\
\hline Total up till primary-level schools & 2,345 & 2,482 & 3,081 & 2,633 & 2,827 \\
\hline Per cent of schools which are up till primary-level & 55.70 & 57.69 & 66.69 & 65.73 & 66.14 \\
\hline Total up till secondary-level schools & 674 & 654 & 575 & 544 & 582 \\
\hline Per cent of schools which are up till secondary-level & 16.01 & 15.20 & 12.45 & 13.58 & 13.62 \\
\hline Total up till high schools & 831 & 756 & 685 & 652 & 698 \\
\hline Per cent of up till high schools & 19.74 & 17.57 & 14.83 & 16.28 & 16.33 \\
\hline Total schools with other levels of schools & 360 & 410 & 279 & 177 & 167 \\
\hline Per cent of schools with other levels of schools & 8.55 & 9.53 & 6.04 & 4.42 & 3.91 \\
\hline \multicolumn{6}{|l|}{ MEDIUM OF INSTRUCTION AT SCHOOL } \\
\hline Total schools with Urdu as medium of instruction & 2,243 & 1,931 & 2,875 & 2,547 & 2,809 \\
\hline $\begin{array}{l}\text { Per cent of schools with Urdu as medium of } \\
\text { instruction }\end{array}$ & 53.28 & 44.89 & 62.23 & 63.58 & 65.72 \\
\hline Total schools with English as medium of instruction & 960 & 409 & 860 & 639 & 652 \\
\hline $\begin{array}{l}\text { Per cent of schools with English as medium of } \\
\text { instruction }\end{array}$ & 22.80 & 9.51 & 18.61 & 15.95 & 15.26 \\
\hline Total schools with Pashto as medium of instruction & 115 & 1,287 & 65 & 84 & 49 \\
\hline $\begin{array}{l}\text { Per cent of schools with Pashto as medium of } \\
\text { instruction }\end{array}$ & 2.73 & 29.92 & 1.41 & 2.10 & 1.15 \\
\hline Total schools with Sindhi as medium of instruction & 594 & 576 & 676 & 612 & 628 \\
\hline $\begin{array}{l}\text { Per cent of schools with Sindhi as medium of } \\
\text { instruction }\end{array}$ & 14.11 & 13.39 & 14.63 & 15.28 & 14.69 \\
\hline $\begin{array}{l}\text { Total schools with other regional language as } \\
\text { medium of instruction }\end{array}$ & 298 & 99 & 144 & 124 & 136 \\
\hline
\end{tabular}




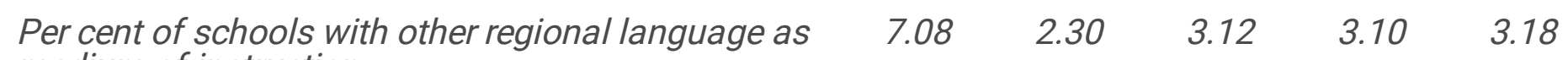
medium of instruction

\section{TEACHERS AT SCHOOL}

Total number of teachers appointed

$\begin{array}{lllll}34714 & 40923 & 34095 & 28314 & 17940\end{array}$

Average number of teachers per school

8.25

$\begin{array}{llll}9.51 & 7.38 & 7.07 & 4.20\end{array}$

TOTAL NUMBER OF SCHOOLS

$4210 \quad 4302 \quad 4620 \quad 4006$

4274

Table 2 shows that the proportion of boys' schools accounted for more than half the schools in the sample in 2013, but this proportion declined to 33.0 per cent by 2018. On the other hand, proportion of girls' schools, which accounted for less than 20 per cent of the total schools in the sample in 2013, increased from 15.9 per cent in 2013 to 51.6 per cent in 2018. Moreover, proportion of mixed schools also declined considerably over the years, accounting for 30.6 per cent of all schools in 2013 and 17.4 per cent of all schools in 2018. Moving on, Table 2 indicates that the majority of schools selected in the sample are up till primary-level, with the proportion of these schools increasing from 55.7 per cent in 2013 to 66.1 per cent in 2018. On the other hand, proportion of schools that are up till secondary-level decreased from 16.0 per cent in 2013 to 13.6 per cent in 2018 whereas proportion of schools up till high school also decreased from 19.7 per cent in 2013 to 16.3 per cent in 2018. Furthermore, majority of schools in the sample have Urdu as the medium of instruction. Over the years the proportion of schools that have Urdu as the medium of instruction increased from 53.3 per cent in 2013 to 65.7 per cent in 2018. While the proportion of schools that have English as the medium of instruction have declined, the proportion of schools that have a regional language as their medium of instruction i.e. Pashto, Sindhi or any other language have also remained constant or slightly decreased. Proportion of schools that have English as the medium of instruction decreased from 22.8 per cent in 2013 to 15.3 per cent in 2018. Finally, the average number of teachers per school declined considerably from an average of 8.3 teachers per school in 2013 to an average of 4.2 teachers per school in 2018.

\section{Infrastructure-specific characteristics}

Descriptive statistics on infrastructure-specific characteristics are presented in Table 3. Infrastructurespecific characteristics are defined as facilities available at individual schools. These facilities include school having a boundary wall, available drinking water at school, toilet facility at school, electricity availability at school, playground facility at school, available science laboratory at school and availability of books in school library.

Table 3: Year-wise descriptive statistics of infrastructure-specific characteristics 


\begin{tabular}{|llllll|}
\hline Variable & 2013 & 2014 & 2015 & 2016 & 2018 \\
\hline FACILITIES AVAILABLE AT SCHOOL & & & & & \\
\hline Total schools with electricity & - & 2726 & 3049 & 2467 & 2699 \\
\hline Per cent of schools with electricity & - & 64.04 & 67.40 & 61.58 & 63.15 \\
\hline Total schools with toilets & 2463 & 2624 & 2835 & 2509 & 2747 \\
\hline Per cent of schools with toilets & 59.68 & 61.48 & 62.13 & 63.09 & 64.27 \\
\hline Total schools with drinking water & 3100 & 2843 & 3081 & 2697 & 3062 \\
\hline Per cent of schools with drinking water & 74.95 & 66.64 & 67.79 & 68.04 & 71.64 \\
\hline Total schools with boundary walls & 2745 & 2964 & 3245 & 2890 & 3199 \\
\hline Per cent of schools with boundary walls & 66.45 & 69.38 & 71.68 & 72.69 & 74.85 \\
\hline Total schools with science laboratory & 748 & 745 & 725 & 642 & 661 \\
\hline Per cent of schools with science laboratory & 18.27 & 17.51 & 16.18 & 16.18 & 15.47 \\
\hline Total schools with books in library & 1114 & 1061 & 970 & 652 & 840 \\
\hline Per cent of schools with books in library & 27.12 & 24.92 & 21.58 & 16.44 & 19.65 \\
\hline Total schools with playground & 1759 & 1811 & 2075 & 1772 & 1853 \\
\hline Per cent of schools with playground & 42.86 & 42.79 & 46.00 & 44.66 & 43.36 \\
\hline
\end{tabular}

Table 3 suggests that the majority of schools selected in the sample have basic facilities such as boundary wall, drinking water, toilets and electricity. Over the years, two-third of the schools in the sample consistently have electricity and toilets, whereas the proportion of schools with drinking water fluctuated from 75.0 per cent in 2013 to 66.6 per cent in 2014 , before rebounding to 71.6 per cent by 2018 . At the same time, the proportion of schools that have a boundary wall increased from 66.5 per cent in 2013 to 74.9 per cent in 2018. On the other hand, a very small proportion of schools have science laboratory and books available in library, with proportion of schools having science laboratory decreasing from 18.3 per cent in 2013 to 15.5 per cent in 2018 and proportion of schools having books in library decreasing from 27.1 per cent in 2013 to 19.7 per cent in 2018. Moreover, proportions of schools having playground have also remained consistent over time, with proportion of schools having playground being 42.9 per cent in 2013 and 43.4 per cent in 2018.

\section{Estimation Model}

To estimate the effectiveness of the policy regarding power supply to schools through solar energy, we treat the announcement of the policy in 2015 as a stimulus, and apply a difference-in-difference identification strategy. This estimation technique relies on the differential changes in enrolment of 
schools belonging to districts in Punjab, where the policy was implemented, and enrolment of schools belonging to districts from elsewhere in Pakistan, where the policy was not implemented. As a result, schools from Punjab are classified as part of the treatment group i.e. treated schools, whereas schools from elsewhere in Pakistan are classified as part of the control group i.e. control schools. This leads to 5,444 schools from Punjab being part of the treatment group while 15,968 schools from elsewhere in Pakistan are part of the control group. The estimation model can be written as below:

Enrolment $_{i, d, t}=\beta_{0}+\beta_{1}$ Province $_{i, d}+\beta_{2}$ Year $_{t}+\beta_{3}\left(\right.$ Province $_{i, d}$ Year $\left._{t}\right)+X^{\prime}+\epsilon_{i, d, t}$

where Enrolment $t_{i, d, t}$ is the response measure of the outcome variable, representing total enrolment at school $i$ belonging to district $d$ in year $t$, where $t$ represents year 2013, 2014, 2015, 2016 and 2018. Enrolment in each school for year 2013, 2014 and 2015 is observed before the announcement of the policy, whereas enrolment in each school for year 2016 and 2018 is observed after the announcement of the policy.

Province $_{i, d}$ is a binary variable that equals 1 if school $i$ in district $d$ is located in Punjab, the province where the policy regarding power supply to schools through solar energy was announced. Schools that fall into the binary category of 1 are classified as treated schools. The binary variable equals 0 if school $i$ in district $d$ is not located in Punjab, but elsewhere in Pakistan. Schools that fall into the binary category of 0 are classified as control schools. The policy regarding power supply to schools through solar energy would not be applicable to control schools.

Year $_{t}$ is a binary variable that equals 1 when observations correspond to years after the announcement of the policy i.e. year 2016 and 2018. It equals 0 when observations correspond to years before the announcement of the policy i.e. year 2013, 2014 and 2015. The coefficient of the interaction term (Province $_{i, d}{ }^{*}$ Year $\left._{t}\right), \beta_{3}$, measures the differential impact of the policy on the enrolment of schools in Punjab with the enrolment of schools elsewhere in Pakistan. Hence, $\beta_{3}$ highlight the effectiveness of the policy regarding power supply to schools through solar energy.

The set of control variables $X_{i, d, t}^{\prime}$ include school-specific characteristics and infrastructure-specific characteristics. School-specific characteristics control for level of teaching at school, type of school, medium of instruction at school, and number of teachers at school. Level of teaching is defined as an ordinal variable that indicates whether school $i$ belonging to district $d$ in year $t$ is only up till primary-level (equals one), or up till middle-level (equals two), or up till high-school (equals three) or any other classification (equals four). Moreover, type of school is defined as an ordinal variable that indicates whether school $i$ belonging to district $d$ in year $t$ is an only boys school (equals one), or an only girls school (equals two) or a mixed-gender school (equals three). Furthermore, medium of instruction is also defined as an ordinal variable that indicates whether learning at school $i$ belonging to district $d$ in year $t$ is in English (equals one), or in Urdu (equals two), or in regional language Pashto (equals three) and Sindhi (equals four), or in any other regional language (equals five). Lastly, number of teachers at school represents the total appointed teachers in school $i$ belonging to district $d$ in year $t$. 
Moving on, infrastructure-specific characteristics controls for the facilities available at each school $i$ belonging to district $d$ in year $t$. The controls are binary variables, each variable individually representing whether school $i$ belonging to district $d$ in year $t$ has electricity available, toilet facility, a boundary wall, available drinking water, availability of books in library, playground facility and available science laboratory. Each binary variables takes a value equal to one if the facility is available at school, otherwise the binary takes a value equals to zero.

Finally, our estimation equation also includes district dummies and time dummies as controls for each individual district and year, to account for any variation in enrolment due to district-specific or yearspecific characteristics. $\varepsilon_{i, d, t}$ is the error term.

\section{Results}

We first provide results for the effectiveness of the policy regarding power supply to schools through solar energy on enrolment of all schools. We examine whether installing solar panels at schools in Punjab resulted in increased enrolment, in comparison to schools elsewhere in Pakistan.

Table 4 provides results for the OLS estimations with enrolment as dependent variable and normal standard errors in Column (1), robust standard errors in Column (2) and clustered standard errors at province level in Column (3). Province*Year is the independent variable of interest which is defined as the interaction between Province $_{i, d}$ and Year $_{t}$. Control variables include level of teaching at school, type of school, medium of instruction at school, total appointed teachers at school and binary variables for whether a school has electricity, toilet, boundary wall, drinking water, books in library, playground and science laboratory. Sample sizes are 13,884 schools for Columns (1) till (3).

Table 4: Impact of policy regarding power supply to schools through solar energy on enrolment of all schools 


\begin{tabular}{|c|c|c|c|}
\hline & \multicolumn{3}{|c|}{ Outcome Variable $=$ Total Enrolment at School } \\
\hline & (1) & $(2)$ & (3) \\
\hline \multirow[t]{2}{*}{ Province } & -17.92 & -17.92 & $-17.92^{\star \star}$ \\
\hline & $(22.12)$ & $(17.74)$ & $(6.75)$ \\
\hline \multirow[t]{2}{*}{ Year } & $52.24 * \star \star$ & $52.24 * \star \star$ & $52.24 * \star$ \\
\hline & $(4.01)$ & $(3.81)$ & $(15.13)$ \\
\hline \multirow[t]{2}{*}{ Province*Year } & $48.46 * \star \star$ & $48.46 * \star \star$ & $48.46 * \star *$ \\
\hline & (6.13) & $(7.28)$ & $(5.99)$ \\
\hline CONTROLS & YES & YES & YES \\
\hline STANDARD ERRORS & NORMAL & ROBUST & CLUSTER \\
\hline OBSERVATIONS & 13,884 & 13,884 & 13,884 \\
\hline
\end{tabular}

Notes: OLS estimations with enrolment as dependent variable with normal standard errors in Column (1), robust standard errors in Column (2) and clustered standard errors at province level in Column (3).

Province*Year is the independent variable of interest which is defined as the interaction between province and year. Control variables include level of teaching at school, type of school, medium of instruction at school, total appointed teachers at school and binary variables for whether a school has electricity, toilet, boundary wall, drinking water, books in library, playground and science laboratory. Sample sizes are 13,884 for Columns (1) till (3).

*** Significant at $1 \%$ level, ** significant at $5 \%$ level, * significant at $10 \%$ level.

The positive coefficient of Province*Year in Column (1) in Table 4 is significant at 1 per cent level, suggesting strong evidence that the policy of installing solar panels at schools in Punjab was highly effective in increasing enrolment at schools. This means, average enrolment per school in Punjab increased by 48.5 students, compared to average enrolment per school elsewhere in Pakistan, after the implementation of the policy. When standard errors are made robust in Column (2) to account for any bias that may be present due to heteroscedasticity, the results are still significant at 1 per cent level. Even when standard errors are clustered on the province level in Column (3) to allow for correlation in observations within each province, the results are significant at 1 per cent level. This provides conclusive that the policy regarding power supply to schools in Punjab through solar energy was highly effective as it led to an increase in average enrolment per school.

We now provide results for the effectiveness of the policy on enrolment of boys' schools specifically. Table 5 provides results for the OLS estimations with enrolment as dependent variable and normal standard errors in Column (1), robust standard errors in Column (2) and clustered standard errors at 
province level in Column (3). Once again, Province* Year is the independent variable of interest, whereas control variables include level of teaching at school, type of school, medium of instruction at school, total appointed teachers at school and binary variables for whether a school has electricity, toilet, boundary wall, drinking water, books in library, playground and science laboratory. Sample sizes are 5,078 schools for Columns (1) till (3).

Table 5: Impact of policy regarding power supply to schools through solar energy on enrolment of boys' schools

\begin{tabular}{|c|c|c|c|}
\hline & \multicolumn{3}{|c|}{ Outcome Variable $=$ Total Enrolment at School } \\
\hline & (1) & (2) & (3) \\
\hline \multirow[t]{2}{*}{ Province } & 17.92 & 17.92 & $17.92^{\star \star *}$ \\
\hline & (37.35) & $(37.72)$ & $(4.82)$ \\
\hline \multirow[t]{2}{*}{ Year } & 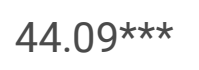 & $44.09 * \star \star$ & $44.09 *$ \\
\hline & $(5.87)$ & $(5.86)$ & (19.49) \\
\hline \multirow[t]{2}{*}{ Province*Year } & $24.13^{\star \star}$ & $24.13^{* *}$ & $24.13^{\star *}$ \\
\hline & $(9.88)$ & (10.78) & $(9.08)$ \\
\hline CONTROLS & YES & YES & YES \\
\hline STANDARD ERRORS & NORMAL & ROBUST & CLUSTER \\
\hline OBSERVATIONS & 5,078 & 5,078 & 5,078 \\
\hline
\end{tabular}

Notes: OLS estimations with enrolment as dependent variable with normal standard errors in Column (1), robust standard errors in Column (2) and clustered standard errors at province level in Column (3). Province*Year is the independent variable of interest which is defined as the interaction between province and year. Control variables include level of teaching at school, type of school, medium of instruction at school, total appointed teachers at school and binary variables for whether a school has electricity, toilet, boundary wall, drinking water, books in library, playground and science laboratory. Sample sizes are 5,078 for Columns (1) till (3).

*** Significant at $1 \%$ level, ** significant at $5 \%$ level, * significant at $10 \%$ level.

The positive coefficient of Province*Year in Column (1) in Table 5 is significant at 5 per cent level, suggesting strong evidence that the policy of installing solar panels at schools in Punjab was highly effective in increasing enrolment at boys' schools. Average enrolment per school for boys' school in Punjab increased by 24.1 students, compared to average enrolment per school for boys' school elsewhere in Pakistan, after the implementation of the policy. When standard errors are made robust in Column (2), 
and clustered on the province level in Column (3), the results are significant at 5 per cent level. This means that policy regarding power supply to schools in Punjab through solar energy was successful in increasing average enrolment preschool for boys' schools.

We now provide results for the effectiveness of the policy on enrolment of girls' schools specifically. Table 5 provides results for the OLS estimations with enrolment as dependent variable and normal standard errors in Column (1), robust standard errors in Column (2) and clustered standard errors at province level in Column (3). Once again, Province*Year is the independent variable of interest, whereas control variables include level of teaching at school, type of school, medium of instruction at school, total appointed teachers at school and binary variables for whether a school has electricity, toilet, boundary wall, drinking water, books in library, playground and science laboratory. Sample sizes are 5,764 schools for Columns (1) till (3).

Table 6: Impact of policy regarding power supply to schools through solar energy on enrolment of girls' schools

\begin{tabular}{|c|c|c|c|}
\hline & \multicolumn{3}{|c|}{ Outcome Variable $=$ Total Enrolment at Schoo } \\
\hline & (1) & (2) & (3) \\
\hline \multirow[t]{2}{*}{ Province } & 9.53 & 9.53 & 9.53 \\
\hline & $(36.32)$ & $(21.56)$ & $(7.17)$ \\
\hline \multirow[t]{2}{*}{ Year } & $52.71 * \star \star$ & 52.71 ** & $52.71 * \star \star$ \\
\hline & $(8.61)$ & $(8.94)$ & $(8.25)$ \\
\hline \multirow[t]{2}{*}{ Province*Year } & $47.94 * * *$ & $47.94 * * *$ & $47.94^{\star * \star}$ \\
\hline & $(9.69)$ & (11.51) & $(6.26)$ \\
\hline CONTROLS & YES & YES & YES \\
\hline STANDARD ERRORS & NORMAL & NORMAL & NORMAL \\
\hline OBSERVATIONS & 5,764 & 5,764 & 5,764 \\
\hline
\end{tabular}

Notes: OLS estimations with enrolment as dependent variable with normal standard errors in Column (1), robust standard errors in Column (2) and clustered standard errors at province level in Column (3). Province*Year is the independent variable of interest which is defined as the interaction between province and year. Control variables include level of teaching at school, type of school, medium of instruction at school, total appointed teachers at school and binary variables for whether a school has electricity, toilet, boundary wall, drinking water, books in library, playground and science laboratory. Sample sizes are 5,764 for Columns (1) till (3). 
$\star \star \star$ Significant at $1 \%$ level, $* \star$ significant at $5 \%$ level, * significant at $10 \%$ level.

The positive coefficient of Province*Year in Column (1) in Table 6 is significant at 1 per cent level, suggesting strong evidence that the policy of installing solar panels at schools in Punjab was highly effective in increasing enrolment at girls' schools. Average enrolment per school for girls' school in Punjab increased by 47.9 students, compared to average enrolment per school for girls' school elsewhere in Pakistan, after the implementation of the policy. When standard errors are made robust in Column (2), and clustered on the province level in Column (3), the results are significant at 1 per cent level. This means that policy regarding power supply to schools in Punjab through solar energy was also successful in increasing average enrolment preschool for girls' schools.

Finally, we now provide results for the effectiveness of the policy on enrolment of mixed schools specifically. Table 5 provides results for the OLS estimations with enrolment as dependent variable and normal standard errors in Column (1), robust standard errors in Column (2) and clustered standard errors at province level in Column (3). Once again, Province ${ }^{\star} Y e a r$ is the independent variable of interest, whereas control variables include level of teaching at school, type of school, medium of instruction at school, total appointed teachers at school and binary variables for whether a school has electricity, toilet, boundary wall, drinking water, books in library, playground and science laboratory. Sample sizes are 3,042 schools for Columns (1) till (3).

Table 7: Impact of policy regarding power supply to schools through solar energy on enrolment of mixed schools

\begin{tabular}{|c|c|c|c|}
\hline & \multicolumn{3}{|c|}{ Outcome Variable = Total Enrolment at School } \\
\hline & (1) & (2) & (3) \\
\hline \multirow[t]{2}{*}{ Province } & -43.29 & -43.29 & $-43.29 * \star \star$ \\
\hline & $(46.82)$ & $(41.32)$ & $(10.16)$ \\
\hline \multirow[t]{2}{*}{ Year } & $54.10 * \star \star$ & $54.10 * \star \star$ & 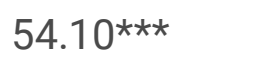 \\
\hline & $(15.45)$ & $(17.75)$ & $(10.35)$ \\
\hline \multirow[t]{2}{*}{ Province*Year } & $54.10 * \star \star$ & $54.10 * \star \star$ & $54.10 * \star \star$ \\
\hline & (15.45) & (17.75) & (10.35) \\
\hline CONTROLS & YES & YES & YES \\
\hline STANDARD ERRORS & NORMAL & NORMAL & NORMAL \\
\hline OBSERVATIONS & 3,042 & 3,042 & 3,042 \\
\hline
\end{tabular}


Notes: OLS estimations with enrolment as dependent variable with normal standard errors in Column (1), robust standard errors in Column (2) and clustered standard errors at province level in Column (3).

Province*Year is the independent variable of interest which is defined as the interaction between province and year. Control variables include level of teaching at school, type of school, medium of instruction at school, total appointed teachers at school and binary variables for whether a school has electricity, toilet, boundary wall, drinking water, books in library, playground and science laboratory. Sample sizes are 3,042 for Columns (1) till (3).

$\star \star \star$ Significant at $1 \%$ level, $* \star$ significant at $5 \%$ level, * significant at $10 \%$ level.

The positive coefficient of Province*Year in Column (1) in Table 7 is significant at 1 per cent level, suggesting strong evidence that the policy of installing solar panels at schools in Punjab was highly effective in increasing enrolment at mixed schools. Average enrolment per school for mixed school in Punjab increased by 54.1 students, compared to average enrolment per school for mixed school elsewhere in Pakistan, after the implementation of the policy. When standard errors are made robust in Column (2), and clustered on the province level in Column (3), the results are significant at 1 per cent level. This means that policy regarding power supply to schools in Punjab through solar energy was also successful in increasing average enrolment preschool for mixed schools.

\section{Conclusion}

Climate change is costing the economy billions of dollars each year through business interruption, insured losses, property damage and disruptions in supply chain (Crawford et al., 2020). Going forward, as the impact of climate change worsens, such costs will increase significantly. Thus, the use of renewable energy, in particular solar energy, is crucial in mitigating the negative consequences of climate change.

The adversarial effects of climate change on living conditions, health outcomes and labor productivity are evident. So are the benefits of solar energy in reducing green-house gas emissions, improving air quality, increasing electrification of remote areas and assisting in rural development. However, there is very limited research on how solar energy can increase access to education, and improve educational outcomes. By reducing barriers to entry, and providing cost effective and environmental friendly supplyside alternates, solar energy could be the technological progress needed in overcoming the challenges in accomplishing the Sustainable Development Goals.

By using school level data between 2013-18 from Pakistan, this paper estimates the effectiveness of the policy regarding power supply to schools through solar energy on enrolment. Using a difference-indifference estimation and controlling for school-specific and infrastructure-specific characteristics, we show that average enrolment per school in Punjab increased by 48.5 students, compared to average enrolment per school elsewhere in Pakistan, after the policy of installing solar panels at schools in Punjab was announced. Furthermore, gender-wise breakup of results suggest that the policy resulted in 
increased enrolment for boys' schools, girls' school and mixed-gender schools. The results are consistent when standard errors are normal, robust, or clustered at the province level.

There are certain limitations to the study. Firstly, while this study controls for a variety of school and infrastructure related control variables, it does not account for household-level or student's individual-level information that may impact the coefficients of our estimations. Secondly, issues related to installation of solar panels and costs, direct and indirect, related to converting schools from conventional energy sources to solar energy are not addressed in this study. Thirdly, the mechanisms through which the policy regarding power supply to schools through solar energy effects enrolment, along with mechanisms responsible for the differential impact of the policy on enrolment of boys and girls are not tested in this study. However, this study paves way for future research to be potentially directed towards addressing the limitations of this study, building upon the results presented.

In summary, this study highlights the importance of policies related to solar energy, which is considered a key energy source of the future. Policymakers must acknowledge that, going forward, reliance on solar energy will be crucial in tackling challenges related to social and economic development. Solar energy is associated with improved standard of living of individuals, in particular, and communities, in general, by providing electricity to regions that are either remote or inaccessible, generating environmental friendly electricity with no carbon emissions, using underutilised land, causing less electricity loss and improving grid security. Even for schools, utilizing solar energy will be critical in lowering barriers to entry and improving educational outcomes. Advocating policies linked to greater dependence on solar energy would be imperative in accomplishing the objectives of the Sustainable Development Goals, which, otherwise, will remain more than just a distant reality.

\section{Declaration}

\section{Ethics approval and consent to participate}

Not applicable

\section{Consent for publication}

Not applicable

\section{Availability of data and material}

The datasets used and/or analysed during the current study are available from the corresponding author on reasonable request.

Competing interests

The authors declare that they have no competing interests 
There are no funding resources to declare

Authors' contributions

All authors analyzed and interpreted the data regarding, along with writing, reading and approving the final manuscript.

$\underline{\text { Acknowledgments }}$

Not applicable

\section{References}

Aevarsdottir, Anna Margret, Nicholas Barton, and Tessa Bold. 2017. "The Impacts of Rural Electrification on Labor Supply, Income and Health: Experimental Evidence with Solar Lamps in Tanzania." Internation Growth Centre, 49. 2017.

Ahmed, Nesar, Anna Occhipinti-Ambrogi, and James F. Muir. 2013. "The Impact of Climate Change on Prawn Postlarvae Fishing in Coastal Bangladesh: Socioeconomic and Ecological Perspectives." Marine Policy 39 (May): 224-33.

Aklin, Michaël, Patrick Bayer, S. P. Harish, and Johannes Urpelainen. 2017. "Does Basic Energy Access Generate Socioeconomic Benefits? A Field Experiment with off-Grid Solar Power in India." Science Advances 3 (5): e1602153.

Anand, Priyanka, and Kallidaikurichi Seetharam. 2011. "Climate Change and Living Cities: Global Problems with Local Solutions." In Climate Change and Sustainable Urban Development in Africa and Asia, edited by Belinda Yuen and Asfaw Kumssa, 21-35. Dordrecht: Springer Netherlands.

Anderson, Allison. 2019. "Building Resilience in Education to the Impact of Climate Change." Brookings. 2019.

Arnell, N. W., and N. S. Reynard. 1996. "The Effects of Climate Change Due to Global Warming on River Flows in Great Britain." Journal of Hydrology 183 (3): 397-424.

Associated Press of Pakistan. 2017. "154 Chinese Companies Attend Road-Show for Solarisation of Schools in Punjab." Associated Press Of Pakistan (blog). March 10, 2017.

Aziz, Rashid, and Ahmed Munawar Baseer. 2015. "Pakistan's Power Crisis: The Way Forward." United States Institute of Peace. 2015.

Baldrian, Petr, Jaroslav Šnajdr, Věra Merhautová, Petra Dobiášová, Tomáš Cajthaml, and Vendula Valášková. 2013. "Responses of the Extracellular Enzyme Activities in Hardwood Forest to Soil Temperature and Seasonality and the Potential Effects of Climate Change." Soil Biology and 
Biochemistry, Special Issue: Interactions of Soil Minerals with Organic Components and Microorganisms VII and Enzymes in the Environment IV, 56 (January): 60-68.

Beltramo, Theresa, and David I. Levine. 2013. "The Effect of Solar Ovens on Fuel Use, Emissions and Health: Results from a Randomised Controlled Trial." Journal of Development Effectiveness 5 (2): 178207.

Berry, Helen Louise, Kathryn Bowen, and Tord Kjellstrom. 2010. “Climate Change and Mental Health: A Causal Pathways Framework." International Journal of Public Health 55 (2): 123-32.

Bloem, Martin W., Richard D. Semba, and Klaus Kraemer. 2010. “Castel Gandolfo Workshop: An Introduction to the Impact of Climate Change, the Economic Crisis, and the Increase in the Food Prices on Malnutrition." The Journal of Nutrition 140 (1): 132S-135S.

Bosello, Francesco, Roberto Roson, and Richard S. J. Tol. 2006. "Economy-Wide Estimates of the Implications of Climate Change: Human Health.” Ecological Economics 58 (3): 579-91.

Bourque, François, and Ashlee Cunsolo Willox. 2014. "Climate Change: The next Challenge for Public Mental Health?" International Review of Psychiatry 26 (4): 415-22.

Bradley, Michael J., Susan J. Kutz, Emily Jenkins, and Todd M. O’Hara. 2005. "The Potential Impact of Climate Change on Infectious Diseases of Arctic Fauna." International Journal of Circumpolar Health 64 (5): $468-77$.

Buragohain, Tarujyoti. 2012. "Impact of Solar Energy in Rural Development in India." International Journal of Environmental Science and Development 3 (4): 5.

Burke, Susie E. L., Ann V. Sanson, and Judith Van Hoorn. 2018. "The Psychological Effects of Climate Change on Children." Current Psychiatry Reports 20 (5): 35.

Çetin, Müjgan, and Nilüfer Eğrican. 2011. “Employment Impacts of Solar Energy in Turkey.” Energy Policy, Asian Energy Security, 39 (11): 7184-90.

Chuang, Erica, Jessie Pinchoff, and Stephanie Psaki. 2018. "How Natural Disasters Undermine Schooling." Brookings. 2018.

Climate Action. 2017. "20,000 Schools to Install Rooftop Solar in Pakistan - Climate Action." Climate Action. 2017.

Climate Central. 2019. “800,000 Years of Carbon Dioxide.” Climate Central. 2019.

Crawford, Victoria, and Lindsey Prowse. 2020. “Climate Resilience Will Make or Break Businesses. Here's Why." World Economic Forum. 2020.

Denchak, Melissa. 2017. "Global Climate Change: What You Need to Know." NRDC. 2017. 
Faiers, Adam, and Charles Neame. 2006. "Consumer Attitudes towards Domestic Solar Power Systems." Energy Policy 34 (14): 1797-1806.

Fountain, Henry. 2020. "Climate Change Affected Australia's Wildfires, Scientists Confirm." The New York Times, March 4, 2020.

Fritsche, Immo, J. Christopher Cohrs, Thomas Kessler, and Judith Bauer. 2012. "Global Warming Is Breeding Social Conflict: The Subtle Impact of Climate Change Threat on Authoritarian Tendencies." Journal of Environmental Psychology 32 (1): 1-10.

Fritze, Jessica G., Grant A. Blashki, Susie Burke, and John Wiseman. 2008. "Hope, Despair and Transformation: Climate Change and the Promotion of Mental Health and Wellbeing." International Journal of Mental Health Systems 2 (1): 13.

Galey, Patrick. 2019. “Climate Impacts 'to Cost World \$7.9 Trillion' by 2050.” Phys. Org. 2019.

Geo News. 2014. "Solar Panels to Be Installed in Punjab Schools: Shahbaz." Geo News. 2014.

Haines, A., R. S. Kovats, D. Campbell-Lendrum, and C. Corvalan. 2006. "Climate Change and Human Health: Impacts, Vulnerability and Public Health.” Public Health 120 (7): 585-96.

Haurin, Sarah. 2017. “How Climate Change Limits Educational Access.” Phys.Org. 2017.

Institute for Sustainable Energy Policies. 2019. "Share of Renewable Energy Power in Japan, 2018 (Preliminary Report)." Institute for Sustainable Energy Policies. April 5, 2019.

Jacobson, Arne. 2007. "Connective Power: Solar Electrification and Social Change in Kenya." World Development 35 (1): 144-62.

Kinney, Patrick L., Marie S. O'Neill, Michelle L. Bell, and Joel Schwartz. 2008. "Approaches for Estimating Effects of Climate Change on Heat-Related Deaths: Challenges and Opportunities." Environmental Science \& Policy 11 (1): 87-96.

Lloyd Simon J., Kovats R. Sari, and Chalabi Zaid. 2011. "Climate Change, Crop Yields, and Undernutrition: Development of a Model to Quantify the Impact of Climate Scenarios on Child Undernutrition." Environmental Health Perspectives 119 (12): 1817-23.

Mekhilef, S., R. Saidur, and A. Safari. 2011. "A Review on Solar Energy Use in Industries." Renewable and Sustainable Energy Reviews 15 (4): 1777-90.

Mondal, Alam Hossain, and Dieter Klein. 2011. "Impacts of Solar Home Systems on Social Development in Rural Bangladesh." Energy for Sustainable Development 15 (1): 17-20.

Morton, John F. 2007. "The Impact of Climate Change on Smallholder and Subsistence Agriculture." Proceedings of the National Academy of Sciences 104 (50): 19680-85. 
Nunez, Christina. 2014. “How Green Are Those Solar Panels, Really?” National Geographic News. November 11, 2014.

Pakistan Today. 2014. "Shahbaz Explores Energy Prospects in China - Pakistan Today." Pakistan Today. 2014.

Pakistan Today. 2015. "10,000 Schools Being Shifted to Solar Energy in Punjab." Pakistan Today. 2015.

Parry, M. L, C Rosenzweig, A Iglesias, M Livermore, and G Fischer. 2004. "Effects of Climate Change on Global Food Production under SRES Emissions and Socio-Economic Scenarios." Global Environmental Change, Climate Change, 14 (1): 53-67.

Patz, Jonathan A., Diarmid Campbell-Lendrum, Tracey Holloway, and Jonathan A. Foley. 2005. "Impact of Regional Climate Change on Human Health." Nature 438 (7066): 310-17.

Pjeczka, Krisztina. 2018. "Reducing the Land Use Impact of Solar Energy - a Triple Win for Climate, Agriculture, and Biodiversity." Yale Environment Review. September 14, 2018.

Randell, Heather, and Clark Gray. 2016. "Climate Variability and Educational Attainment: Evidence from Rural Ethiopia." Global Environmental Change 41 (November): 111-23.

Randell, Heather, and Clark Gray. 2019. "Climate Change and Educational Attainment in the Global Tropics." Proceedings of the National Academy of Sciences 116 (18): 8840-45.

Ranjan, Priyantha, So Kazama, and Masaki Sawamoto. 2006. "Effects of Climate Change on Coastal Fresh Groundwater Resources." Global Environmental Change 16 (4): 388-99.

Ranjan Senapati, Manas, Bhagirathi Behera, and Sruti Ranjan Mishra. 2013. "Impact of Climate Change on Indian Agriculture \&amp; Its Mitigating Priorities." American Journal of Environmental Protection 1 (4): 109-11.

Ritchie, Hannah, and Max Roser. 2017. "CO囚 and Greenhouse Gas Emissions." Our World in Data. 2017.

Rohayem, J. 2009. "Norovirus Seasonality and the Potential Impact of Climate Change." Clinical Microbiology and Infection 15 (6): 524-27.

Sachs, Wolfgang. 2008. "Climate Change and Human Rights." Development 51 (3): 332-37.

Saseendran, S. A., K. K. Singh, L. S. Rathore, S. V. Singh, and S. K. Sinha. 2000. "Effects of Climate Change on Rice Production in the Tropical Humid Climate of Kerala, India." Climatic Change 44 (4): 495514.

Scheffran, Jürgen, and Antonella Battaglini. 2011. "Climate and Conflicts: The Security Risks of Global Warming." Regional Environmental Change 11 (1): 27-39. 
Shaw, Ethan. 2017. "Positive Effects of Solar Energy.” Sciencing. 2017.

Sheffield, Perry E., Simone A. M. Uijttewaal, James Stewart, and Maida P. Galvez. 2017. "Climate Change and Schools: Environmental Hazards and Resiliency." International Journal of Environmental Research and Public Health 14 (11): 1397.

Shellenberger, Michael. 2018. "If Solar Panels Are So Clean, Why Do They Produce So Much Toxic Waste?" Forbes. 2018

Silverstein, Ken. 2019. "Solar Energy Could Light Up Africa And Global Businesses See Opportunity." Forbes. 2019.

St.Clair, Samuel B., and Jonathan P. Lynch. 2010. "The Opening of Pandora's Box: Climate Change Impacts on Soil Fertility and Crop Nutrition in Developing Countries." Plant and Soil 335 (1): 101-15.

Stephen. 2017. "Hidden Costs of Climate Change Running Hundreds of Billions a Year." National Geographic News. 2017.

The Express Tribune. 2014. "Let There Be Light: 46 Solar Power Projects Planned in the Punjab.” The Express Tribune. 2014.

The Express Tribune. 2015. “Renewable Resource: Shahbaz Says 4,000 Schools Set to Go Solar.” The Express Tribune. 2015.

The News. 2016. “Shahbaz Hails Shifting of Schools on Solar Energy.” The News. 2016.

Thompson, Adeboyejo Aina, Lirvhuwani Matamale, and Shonisani Danisa Kharidza. 2012. "Impact of Climate Change on Children's Health in Limpopo Province, South Africa." International Journal of Environmental Research and Public Health 9 (3): 831-54.

Tirado, M. C., D. Hunnes, M. J. Cohen, and A. Lartey. 2015. “Climate Change and Nutrition in Africa." Journal of Hunger \& Environmental Nutrition 10 (1): 22-46.

Tol, Richard S. J. 2009. “The Economic Effects of Climate Change.” Journal of Economic Perspectives 23 (2): $29-51$.

Tsoutsos, Theocharis, Niki Frantzeskaki, and Vassilis Gekas. 2005. “Environmental Impacts from the Solar Energy Technologies." Energy Policy 33 (3): 289-96.

United Nations. 2014. “The Cost of Climate Change.” UNFCCC. 2014.

Vardoulakis, Sotiris, Chrysanthi Dimitroulopoulou, John Thornes, Ka-Man Lai, Jonathon Taylor, Isabella Myers, Clare Heaviside, et al. 2015. "Impact of Climate Change on the Domestic Indoor Environment and Associated Health Risks in the UK." Environment International 85 (December): 299-313. 
Wehrmann, Benjamin. 2018. "Solar Power in Germany - Output, Business \& Perspectives." Clean Energy Wire. 2018.

Welle, Deutsche. 2020. "Record Shrinking of Greenland's Ice Sheet Raises Sea Levels.” EcoWatch. 2020.

Wheeler, Tim, and Joachim von Braun. 2013. "Climate Change Impacts on Global Food Security." Science 341 (6145): 508-13.

Wiser, Ryan, Dev Millstein, Trieu Mai, Jordan Macknick, Alberta Carpenter, Stuart Cohen, Wesley Cole, Bethany Frew, and Garvin Heath. 2016. "The Environmental and Public Health Benefits of Achieving High Penetrations of Solar Energy in the United States." Energy 113 (October): 472-86.

Worland, Justin. 2017. “Climate Change Will Make Parts of South Asia Unlivable.” Time. 2017.

World Health Organization. 2018. “Climate Change and Health.” World Health Organization. 2018.

Wu, Xiaoxu, Yongmei Lu, Sen Zhou, Lifan Chen, and Bing Xu. 2016. "Impact of Climate Change on Human Infectious Diseases: Empirical Evidence and Human Adaptation." Environment International 86 (January): 14-23.

Xu, Jianchu, R. Edward Grumbine, Arun Shrestha, Mats Eriksson, Xuefei Yang, Yun Wang, and Andreas Wilkes. 2009. "The Melting Himalayas: Cascading Effects of Climate Change on Water, Biodiversity, and Livelihoods." Conservation Biology 23 (3): 520-30.

Zhou, Xiao-Nong, Guo-Jing Yang, Kun Yang, Xian-Hong Wang, Qing-Biao Hong, Le-Ping Sun, John B. Malone, Thomas K. Kristensen, N. Robert Bergquist, and Jürg Utzinger. 2008. "Potential Impact of Climate Change on Schistosomiasis Transmission in China." The American Journal of Tropical Medicine and Hygiene 78 (2): 188-94.

\section{Figures}




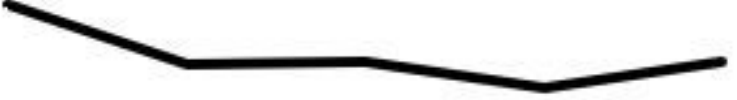

250

200

150

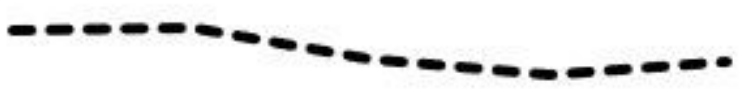

100

50

0

$\begin{array}{lllll}2013 & 2014 & 2015 & 2016 & 2018\end{array}$

Enrolment per year of schools in Punjab

- Enrolment per year of schools elsehwere in Pakistan

\section{Figure 1}

Average enrolment per school of all schools

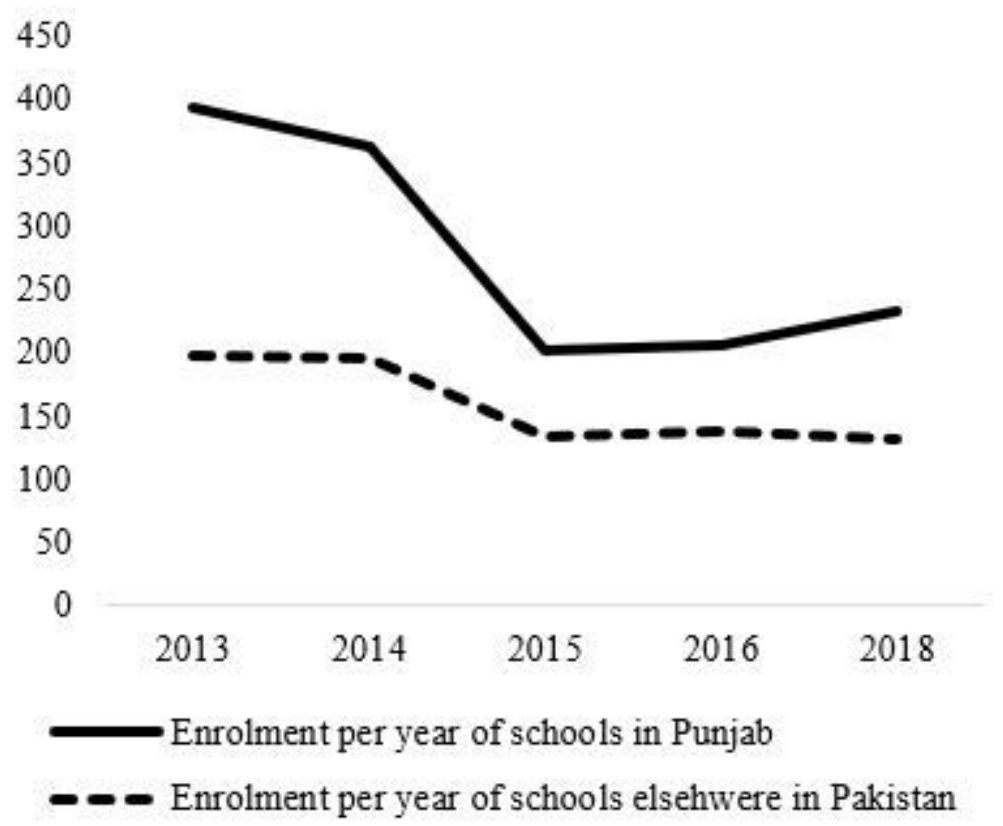

Figure 2

Average enrolment per school of boys' schools 
450

400

350

300

250

200

150

100

50

0

$2013 \quad 2014 \quad 2015 \quad 2016 \quad 2018$

Enrolment per year of schools in Punjab

- Enrolment per year of schools elsehwere in Pakistan

\section{Figure 3}

Average enrolment per school of girls' schools

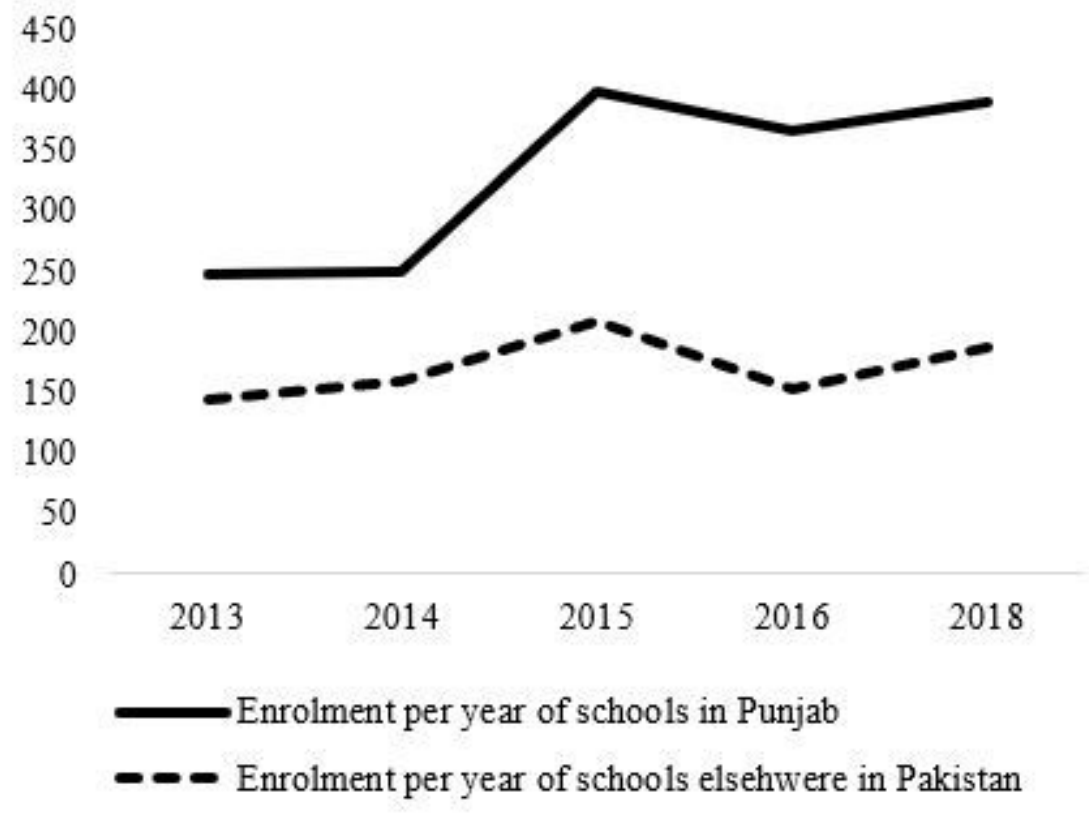

\section{Figure 4}

Average enrolment per school of mixed schools 